\title{
First Mover or Higher Quality? Optimal Product Strategy in Markets with Positive Feedbacks
}

\author{
PJ Lamberson* \\ Scott E. Page ${ }^{\dagger}$
}

\begin{abstract}
Conventional wisdom holds that in markets with positive feedbacks being first to market can matter more than product quality. In this paper, we test that intuition within a generalized Pólya urn model. We find that if we assume constant feedbacks, in the long run higher quality products dominate the market regardless of initial market shares, contradicting the common wisdom. However, when we allow for variable feedbacks, we find that initial advantages persist almost indefinitely. Thus, the choice of whether to rush to market or focus on quality depends on market characteristics such as whether the positive feedbacks result from more consistent returns to scale or from more variable social influences.
\end{abstract}

*UCLA. lamberson@ucla.edu.

†University of Michigan, External Faculty Santa Fe Institute. spage@umich.edu.

This is the author manuscript accepted for publication and has undergone full peer review but has not been through the copyediting, typesetting, pagination and proofreading process, which may lead to differences between this version and the Version of Record. Please cite this article as doi: $10.1111 /$ jems.12231 


\section{Introduction}

Positive feedbacks, including network externalities, learning curves, information cascades, increasing returns, and social learning, reinforce established leads. Conventional wisdom suggests that in these markets opening an early gap on competitors is critical to long run success. And yet, late entrants, Facebook, Google, and the iPhone dominate industries with strong positive feedbacks.

The dominance of Facebook's social network, Google's search engine, and Apple's iPhone support a more standard economic logic: in the long run quality dominates. In this paper, we compare these competitive strategies in markets with positive feedbacks. We ask which matters most: getting to market first or having the highest quality product? We find that the answer depends on market characteristics that influence whether the feedbacks will be constant or variable.

The strategy literature predominantly supports the first strategy, arguing that in positive feedback markets firms should enter early and employ aggressive tactics for building an installed base. While actions such as deep discounting, heavy advertising, and rapid expansion are costly in the short term, they can pay off in the medium to long term by eliminating competitors and "locking-in" the market. ${ }^{1}$

\footnotetext{
${ }^{1}$ See, for example, Spence $(1979,1981)$; Fudenberg and Tirole (1983, 2000); Grindley (1990); Besen and Farrell (1994); Arthur (1996); Shapiro and Varian (1999); Farrell and Klemperer (2006). Many of these authors take care to note that the prescription relies on certain competitive conditions being satisfied, the key criterion being that the positive feedbacks do not spillover (too much) to other competing firms. For example, in the case of network externalities individual products must be highly incompatible (Katz and Shapiro, 1985; Fudenberg and Tirole, 2000). In the case of the learning curve, knowledge spillover between firms reduces the advantages gained through aggressive strategies (Fudenberg and Tirole, 1983; Ghemawat and Spence, 1985). Because feedbacks in the model we employ accrue only to a single firm, the model gives the aggressive strategy the benefit of the doubt.
} 
Some research even suggests that markets can lock-in to inferior technologies although superior alternatives are available (e.g. David, 1985; Farrell and Saloner, 1985; Arthur, 1989; Cowan, 1990; Cowan and Gunby, 1996). Thus, it may be worthwhile to allocate resources away from quality-focused activities like market research, product development, and testing in favor of early product launches and aggressive marketing (Watts and Hasker, 2006). In describing what strategies are not important for competition in a standards contest Grindley (1990) goes so far as to say, “... technical development and product quality are surprisingly unimportant."

A second collection of scholars challenges that inference and argues that, in the long run, markets select the best products (Liebowitz and Margolis, 1990, $1994,1995,2001)$. They advocate a strategy of focusing on quality rather than being first to market. From this perspective the advantages gained through aggressive marketing tactics are not only costly, but fleeting, and improvements in quality should never be sacrificed for early advantage. These scholars dispute historical accounts and theoretical arguments that claim lower quality products can dominate the market. For example, Liebowitz and Margolis (1990) question the conventional wisdom that the Dvorak keyboard layout is technically superior to the more standard QWERTY keyboard, while David (1985) and others cite this as a prime example of lock-in to an inferior technology. The "quality always dominates" argument is supported by an experimental study conducted by Hossain and Morgan (2009), which found that even if an inferior product enjoyed a substantial first mover advantage, the superior alternative always won out in the long run. 
To tackle the question of whether higher quality or early entry matter most, we employ the standard framework for modeling positive feedbacks, the generalized Pólya urn model (Johnson and Kotz, 1977; Pemantle, 2007) which we analyze using both mathematical and computational techniques. Urn models are a classic (and, by students, often loathed) tool of basic probability and statistics courses in which probabilities are represented by the chances of pulling a ball of a given color out of an urn filled with balls of various colors. Social and market forces are represented by rules for adding or subtracting balls from the urn based on the color of the drawn ball.

The standard Pólya urn model is a special case in which there are two colors of balls and when a ball of a given color is drawn it is replaced along with an additional ball of the same color. This simple framework has become the canonical representation of processes with positive feedbacks in applications ranging from markets (Arthur, Ermoliev and Kaniovski, 1983) to the development of neurons in the brain (Khanin and Khanin, 2001). The generalized Pólya urn model extends this to situations with more than two colors, and if a ball of color $c$ is drawn, it is returned to the urn along with $\rho_{c}>0$ balls of color $c$. When modeling product competition, the parameter $\rho$ functions as a proxy for quality: purchases of higher quality products result in more balls being placed in the urn.

Using this model we find that, contrary to the recommendations of the dominant strand of the strategy literature, establishing an early lead proves less effective than producing a higher quality product in relatively short time, and, therefore, in the long term as well. Firms that garner large initial sales are quickly overtaken 
by those with higher quality, and as time goes to infinity the higher quality product almost surely captures the entire market. Thus, the success of products like Facebook, Google, and the iPhone may potentially be explained by the fact that these firms simply had better products, and thus higher feedbacks, than their once larger competitors.

We then extend the model to include stochastic feedbacks. For reasons of tractability and parsimony, most models of positive feedback markets assume that each purchase has the same effect. That assumption makes sense if the feedbacks result from, say, cost reductions due to returns to scale. ${ }^{2}$ If, though, the positive feedbacks result from social influence, then heterogeneity of consumer preferences, asymmetries in influence networks, or variance in product quality would create a distribution of positive feedbacks.

This variability might be thought to cancel out; however, here we show that not to be the case. As the variability in feedbacks increases, the durability of an initial advantage does as well. In the limit, the firm with the highest mean feedbacks still almost surely captures the market, but when feedbacks are uncertain, a firm with an initial advantage may dominate for all reasonable time scales. Thus, our model suggests the optimal competitive strategy depends on the nature of the positive feedbacks. In markets in which feedbacks have a high degree of consis-

\footnotetext{
${ }^{2}$ In some models this effect changes over time, but it does so deterministically (e.g. Spence, 1981; Katz and Shapiro, 1985; Kalish and Lilien, 1986). Weyl (2010) and White and Weyl (2016) (discussed further below) consider the impact of deterministic heterogeneity in network effects on equilibrium pricing in am model of multi-sided platform competition. Lamberson and Page (2012) provide a notable exception that considers stochastic feedback heterogeneity in the same spirit as modeled here.
} 
tency or certainty, a quality strategy dominates; in those with variable or uncertain feedbacks, a "get big fast strategy" is more likely to succeed.

Our findings are complementary to a stream of research on what White and Weyl (2016) call "insulated platform competition.” This literature argues that late entrants offering superior products can (and do) retake markets from inferior incumbents through the use of temporary subsidies that incentivize consumer switching (Dybvig and Spatt, 1983; Weyl, 2010; Weyl and White, 2014). In many respects, this "usage revenue later" strategy is like the initial advantage strategy explored in our model in which a firm focuses on building a large installed base, possibly at a cost, in hopes of reaping the rewards from dominating the market later. The difference is that rather than using a get big fast approach to establish an advantage before competing firms gain an upper hand, the insulating strategy is used to overcome an initial deficit after a less attractive alternative has already established a lead. Because higher quality products are preferred, all else equal, the cost to subsidize consumer switching is lower for more efficient products.

Our model takes a starker approach to firm strategy, focusing directly on the relative benefits of establishing an initial advantage versus producing a higher quality product (and later on producing a product with more consistent feedbacks), leaving aside questions of strategic pricing. But, even without pricing our model findings agree with the broad conclusion of the insulated competition literature that lock-in to inefficient outcomes in markets with positive externalities is less likely than may be commonly believed (Weyl and White, 2014). However, our model shows that positive feedbacks alone, without costly "penetration pricing" 
strategies, is sufficient to explain why late entering firms can come from behind to overtake dominant but inferior incumbents. Moreover, our results raise another key variable, the variability in consumer feedbacks, that may interact with product quality to impact the necessity or effectiveness of an insulating strategy.

The horse race structure of our paper implies a tradeoff from entering early or having higher quality. That tradeoff almost certainly exists as more time in product development and testing should produce a higher quality product, with the caveat that a firm might gild the lily. Other strategic decisions need not require a tradeoff. For example, our model suggests that high quality producers also have an incentive to increase the consistency of the positive feedbacks, a strategy we take up in the penultimate section of the paper.

\section{A Model of Markets with Positive Feedbacks}

We model competition among a set of $M$ firms with positive feedbacks using a generalized Pólya urn model (Pemantle, 2007). Similar urn models have been previously employed to study competing firms as we do here (Lamberson and Page, 2012), and a wide range of other phenomena including criminal behavior (Greenberg, 1991), box office success of movies (De Vany and Walls, 1996), the impact of recommender systems (Fleder and Hosanagar, 2009), group problem solving (LiCalzi and Surucu, 2012), the growth of networks such as the world wide web (Levene, Fenner, Loizou and Wheeldon, 2002), and many others (Johnson and Kotz, 1977; Page, 2006; Pemantle, 2007). 
We describe the model using a ball and urn metaphor to build intuition. The formal model allows for such things as the probabilistic addition of fractional balls. An urn contains balls of $M$ different colors. Each color corresponds to one of $M$ competitors in the market. These can be thought of as either products or firms. As we analyze strategic behavior in a market, we refer to the competitors throughout as firms. Let $S_{i}^{t}$ denote the number of balls of color $i$ in the urn at time $t$ for $t=0,1,2, \ldots$ and $R_{i}^{t}=\frac{S_{i}^{t}}{\sum_{j=1}^{M} S_{j}^{t}}$ the fraction of balls of color $i$ at time $t$. To simplify notation we drop the superscript 0 when referring to the initial value of any of the time dependent variables in the model, so the initial state of the urn is given by

$$
S=\left(S_{1}, \ldots, S_{M}\right)
$$

We require $S_{i}>0$ for each $i$.

The state of the urn serves as a gauge of the mood of the market - a firm's proportion of balls in the urn, $R_{i}^{t}$, corresponds to the probability that a consumer at time $t+1$ will purchase a product from firm $i$. Depending on the industry under consideration, the state of the urn may result from consumer reviews on the World Wide Web, word-of-mouth communications, network effects, or publicity. We call a firm's initial share of balls in the urn the firm's initial market presence. Given the structure of the model, a firm that begins with more balls in the urn will have an initial advantage,

At each time $t=1,2, \ldots$, a ball is drawn from the urn, representing a purchase from the firm of the corresponding color. This is formalized by realizing a discrete 
random variable $x^{t}$ that takes values in $\{1, \ldots, M\}$ (we also denote the realization by $x^{t}$ ) where,

$$
\operatorname{Pr}\left(x^{t}=i\right)=R_{i}^{t-1} \quad i \in\{1, \ldots, M\}
$$

The ball is then returned to the urn along with some number of balls of the same color as the drawn ball. These additional balls create a positive feedback, making it more likely that future drawn balls will be of the same color $x^{t}$, i.e. more likely that future consumers will purchase a product from the firm $x^{t}$.

The level of this positive feedback is specified by a vector of transition weights

$$
\rho=\left(\rho_{1}, \ldots, \rho_{M}\right)
$$

Each $\rho_{i}$ is a non-negative real valued random variable with finite support. At each time $t$ an instance of the random variable $\rho_{i}$ is realized (also denoted $\rho_{i}$ ), and

$$
S_{i}^{t}= \begin{cases}S_{i}^{t-1}+\rho_{i} & \text { for } i=x^{t} \\ S_{i}^{t-1} & \text { for } i \neq x^{t}\end{cases}
$$

This positive feedback could result from a variety (or a combination) of mechanisms including word-of-mouth recommendations, increasing returns to scale, diffusion of awareness, or social learning. Modeling these feedbacks as probabilistic allows us to represent situations in which, for example, a consumer chooses to recommend a product with some probability, or where there is variability across consumer recommendations. This assumption extends the canonical urn model, 
which assumes constant feedbacks that occur with certainty. We expect that some sources of positive feedback, such as word-of-mouth, might have more variability than others, such as returns to scale.

As the process unfolds, we keep track of the total sales of each firm, represented by the total number of balls drawn of each color,

$$
X_{i}^{t}=\sum_{s=1}^{t} x^{s}
$$

In our analysis, we examine the consequences on expected market shares of varying assumptions regarding the initial state of the urn and the transition weights on these outcomes in both finite time and in the limit. Mathematically, the anticipated market shares correspond to the expected values of random variables produced by the urn process. We denote the expectation of any of these variables by using a bar, and dependence on the initial state and the transition weights using square brackets. For example,

$$
\bar{X}^{t}[S ; \rho]
$$

denotes the expected outcome vector at time $t$ with initial state $S$ and transition weights $\rho$.

\section{Two Strategies: Initial Advantage and Quality}

Our initial analysis compares two strategies, an initial advantage strategy and a quality strategy. Each of these strategies increases a firm's expected market share 
relative to a competitor. We analyze which results in higher market share. Proofs of all of the results can be found in the supplementary online appendix.

\subsection{Initial Advantage}

The initial advantage strategy is modeled as an increase in a firm's initial share of balls in the urn - the firm's initial market presence. In practice, a firm might increase its initial market presence by being first to market, through advertising, offering discounts to early adopters, or "seeding" the population by giving away samples. Some firms may begin with higher market presence than others because of reputation spillover from previous products. Increasing a firm's initial market presence increases its expected market share after any finite time. (The result is straightforward, but for completeness we prove this as Theorem 1 in the supplementary online appendix.)

The exact probability distribution in the infinite limit assuming all firms have constant transition weights equal to one was derived by Blackwell and MacQueen (1973). They show that if $\rho_{1}=\cdots=\rho_{M} \equiv 1$, then the shares of balls in the urn (and thus the long run market shares) $R_{1}^{t}, \ldots, R_{M}^{t}$ converge almost surely to $R_{1}^{\infty}, \ldots, R_{M}^{\infty}$ with distribution

$$
\frac{\Gamma\left(S_{1}+\cdots+S_{M}\right)}{\Gamma\left(S_{1}\right) \cdots \Gamma\left(S_{d}\right)} \prod_{i=1}^{M}\left(R_{i}^{\infty}\right)^{S_{i}-1}
$$

The multivariate distribution in equation (4) is a Dirichlet distribution with parameters $S_{1}, \ldots, S_{M}$. This distribution has several noteworthy properties. First, 
when all of the firms have equal initial market presence, i.e. $S_{1}=S_{2}=\cdots=S_{M}$, any collection of market shares that sum to one is equally likely to occur. Second, for all values of $S_{1}, \ldots, S_{M}$, all points in the domain of the distribution have positive support. Third, the distribution varies smoothly with the $S_{i}$.

In other words, increasing a firm's initial advantage smoothly transforms the long term probability distribution, but with equal feedbacks there is a positive probability of convergence to any collection of market shares regardless of how far ahead or behind the firms start out. No level of initial advantage results in a guaranteed winner-take-all outcome. Given the abundance of literature linking positive feedbacks with lock-in of a single product, many may find this result surprising. ${ }^{3}$ As we describe in Section 4, the key to locking in the market in the long term is not an initial advantage, but rather a quality advantage.

\subsection{Quality}

We next consider quality. We assume that the level of a firm's feedbacks correlate with quality; the higher the quality of the product, the more individuals who purchase the product recommend it to others. Thus, we model the quality strategy as an increase in the average feedback that results from a single purchase. Intuitively, increasing a firm's positive feedbacks also increases its market share. (The result is straightforward, but for completeness we establish this formally in Theorem

\footnotetext{
${ }^{3}$ The common identification of positive feedback urn models with lock-in most likely comes from the well-known work of Arthur (1989). In Appendix A we explain how Arthur's urn model differs from the standard Pólya urn model and how these differences produce the winner-take-all result absent from the standard model.
} 
2 in the supplementary online appendix.) If we identify higher feedbacks with higher quality, then higher quality products have higher expected market shares after any finite time. We discuss the long term implications of a quality strategy in the next section.

\section{The Horse Race Between Quality and Early Entry}

Having defined two strategies for gaining competitive advantage in markets with positive feedbacks, we turn to a comparison of their relative strength. We show that which strategy provides the greatest advantage depends on the context in predictable ways. In particular, while most strategy recommendations focus on the long run benefits of establishing an initial advantage, we find that the greatest rewards of an increase in initial market presence are realized in the short run. In contrast, we find that the advantages of the quality strategy accrue in the long run.

The distribution in equation (4) shows that in the long run the initial advantage strategy smoothly increases expected market share but cannot guarantee market dominance. An established but rarely cited result (originally proven by Athreya (1969), see also Johnson and Kotz (1977)) from the literature on branching processes implies that a product that dominates on quality necessarily captures the market in the long run regardless of any competitors' initial advantages.

Theorem 1. (Athreya, 1969) If $E\left[\rho_{j}\right]>E\left[\rho_{i}\right]$ for $i \neq j$, then as the number of purchases approaches infinity, firm j's market share approaches one.

Counter to the conventional wisdom, Theorem 1 demonstrates that in the long 
Firm Q Median Share After 100 Sales

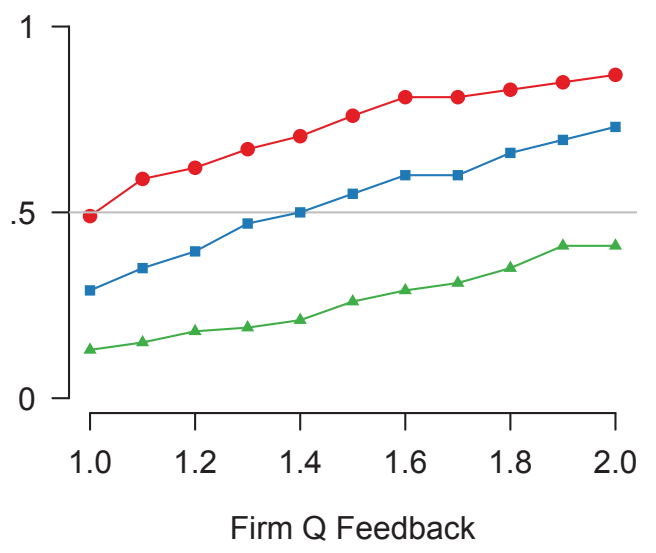

Firm Q Median Share After 10,000 Sales

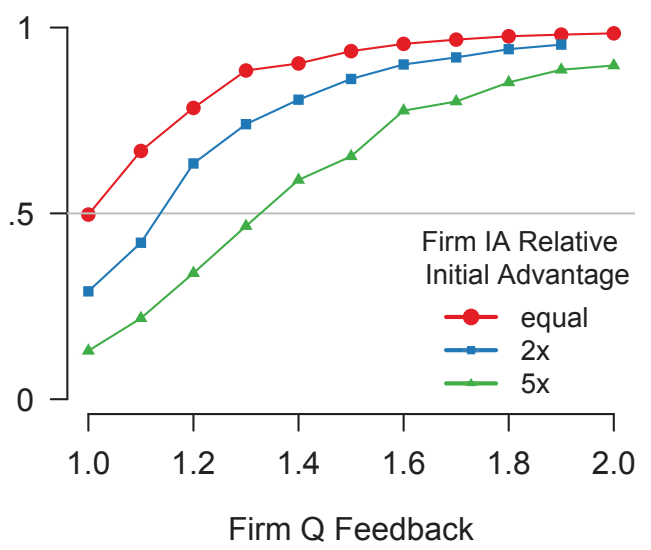

Figure 1: Initial advantage versus Quality (level of feedback). Firm Q has feedbacks ranging from 1 to 2 shown on the horizontal axis. Firm IA has feedback 1 and an equal, double, or five-fold initial advantage represented by the three lines in the graph.

run a superior quality product will overcome any deficit in initial installed base and come to dominate the market. It is important to keep in mind that this theorem describes the limiting distribution. It states that eventually the highest feedback, i.e. highest quality, firm captures the entire market. It gives us no insight into how many periods are required for the highest feedback firm to gain a majority of the market, or what other outcomes are possible or likely in finite time.

To compare the relative advantages of initial advantage and quality in finite time, we examine the outcomes from 1000 simulations of the model with two firms. The first firm, "Firm IA," takes an initial advantage strategy and the second firm, "Firm Q," takes a quality strategy. The initial advantage strategy is modeled 
as an increase in the initial market presence for Firm IA and we vary the firm's initial advantage from an equal to a five fold advantage over Firm Q's initial market presence. Firm Q's quality strategy is modeled by increasing the firm's transition weights from equal up to double the transition weights of Firm IA.

Figure 1 plots the median share for Firm Q for varying strengths of the quality and initial advantage strategies. Whenever the line lies above the .5 level, the quality strategy yields a higher market share in more than half of the simulations. As the figure shows, the advantage of greater initial market presence only endures when the levels of feedback are very similar. After only 100 purchases, the benefits of greater feedbacks dominate those of early advantage for most feedback levels. After 10,000 purchases, even a slight advantage in feedbacks outweighs all but the largest advantages in initial market presence. For example, a firm with $30 \%$ higher feedbacks is effectively on equal footing with a firm that started with a five fold initial advantage.

Notice that while the computational results in Figure 1 depict only two competing firms, a straightforward argument detailed in the following lemma allows us to generalize the intuition to any number of firms.

Lemma 1. The expected sales of a firm competing with $M-1$ other firms is equal to the expected sales of that firm competing with a single other firm,

$$
\bar{X}_{1}^{t}\left[\left(S_{1}, \ldots, S_{M}\right) ;\left(\rho_{1}, \ldots, \rho_{M}\right)\right]=\bar{X}_{1}^{t}\left[\left(S_{1}, \sum_{i=2}^{M} S_{i}\right) ;\left(\rho_{1}, \hat{\rho}_{2}\right)\right]
$$


where

$$
\hat{\rho}_{2}=\rho_{i} \text { with probability } \frac{S_{i}}{\sum_{j=2}^{M} S_{j}}
$$

for each $i=2, \ldots, M$.

This lemma follows immediately from the construction and allows us to reduce the case of a firm competing with $M-1$ other firms to a firm competing with only one other firm. What is perhaps most interesting about the case of more firms is that it tends to have a larger effect on the initial advantage strategy than the quality strategy. This follows from the fact that adding more firms necessarily dilutes the average market share.

Both Theorem 1 and the computational results shown in Figure 1 contradict the dominant thinking for strategy in markets with positive feedbacks where establishing early advantage is the standard recommendation. Scholars urge firms to focus on the "life-cycle" of their products; they suggest that companies should invest money in establishing an installed base and recoup their investments through later sales to locked-in customers (Shapiro and Varian, 1999). Our analysis cautions against this strategy, particularly if investments in the installed base come at the expense of quality improvements that could result in higher feedbacks later. The advantages of an early lead vanish quickly when facing a competitor with higher positive feedbacks. If that early lead is established at a cost to the firm, it may disappear before there is a chance for the investment to pay off. However, as we show in the following section, these implications are not robust in the extended model that allows for variation in the positive feedbacks. 


\section{Uncertainty}

We now extend our analysis by including stochastic feedbacks and analyzing their effect on strategic behavior. Before undertaking that analysis, two comments are in order: one theoretical and one pragmatic. First, recall from the generalized urn model in Section 2 that in the long run stochastic feedbacks don't matter (Theorem 1): the firm with the highest mean feedbacks will dominate the market, regardless of feedback variability. That result does not imply that stochastic feedbacks are irrelevant to the strategic choice between investing in quality or initial advantage, particularly in the short run. In fact, we find that when feedbacks are noisy, initial advantage can outweigh quality differences for a very long time, enough so that pursuing an initial advantage and not higher quality is the better strategy.

This raises the pragmatic question of when we would expect feedbacks to be more or less certain. One would expect feedbacks that result from production externalities, returns to scale, learning by doing, etc... to be less variable. Though the urn model does not explicitly include price, the increased demand for one firm over another could be interpreted as resulting from one firm having a lower price. One would also expect feedbacks in the form of complementarities with other new products to be more certain - demand for a gaming station increases as software developers create more games. More uncertain feedbacks will occur on the demand side. Feedbacks would be expected to have higher variance if the market for the product contains heterogeneous consumers, and if those consumers differ in their number of social contacts, in their uses for the product, or in their 
predispositions to create social spillovers.

For many products, feedbacks will include both stable and stochastic sources. Consider the market for environmentally safe waterproof fabrics, which includes outerwear and upholstery. If two firms introduce new fabrics, each will experience relatively constant feedbacks on the production side such as returns to scale or technological learning curve advancements. The social feedbacks, though, might be high variance, particularly in the outerwear market. Our results will show that the level of feedback uncertainty has implications for strategic choice.

To examine the effect of feedback uncertainty, we repeat the computational experiment of Section 4, but with uncertain rather than fixed feedbacks. We again examine two competing firms, "IA" and "Q," and we keep the expected feedbacks the same as the fixed feedbacks of Section 4, but now rather than receiving a fixed feedback $\rho_{i}$ with probability one (where the value of $\rho_{i}$ depends on the strategy of firm $i$ ), the firms receive $n \rho_{i}$ with probability $1 / n$. Thus, the mean feedbacks are kept the same as in the computations in Section 4, but the variance is increased. In other words, these new feedbacks are a mean preserving spread of the previous feedbacks.

We run the model 1000 times for varying values of $n$ and again examine the median shares of the two firms after 10,000 sales. Figure 2 depicts the results. In the right panel of Figure 1, we saw that with certain feedbacks a $30 \%$ feedback advantage was sufficient to beat a five fold initial advantage. When feedbacks are uncertain Figure 2 tells a different story. In the left panel when feedbacks occur for one out of every four purchases on average, it takes more than a $70 \%$ feedback 


\section{Firm Q Median Share After 10000 Sales Feedback Probability $1 / 4$}

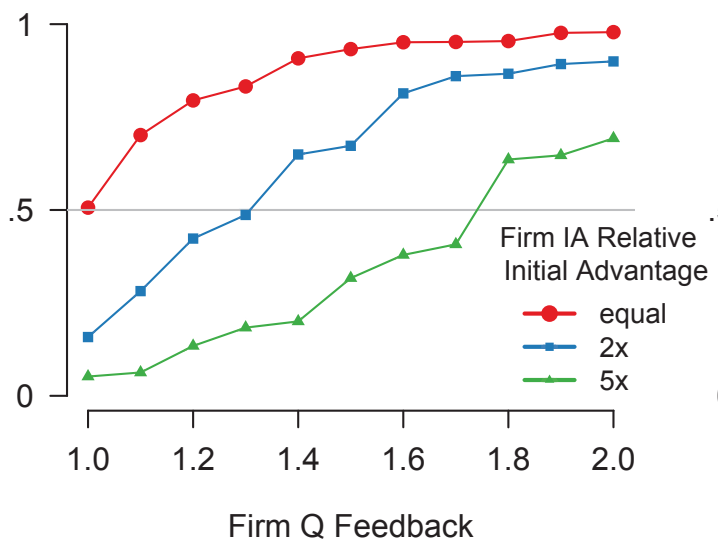

Firm Q Median Share After 10,000 Sales Feedback probability $1 / 10$

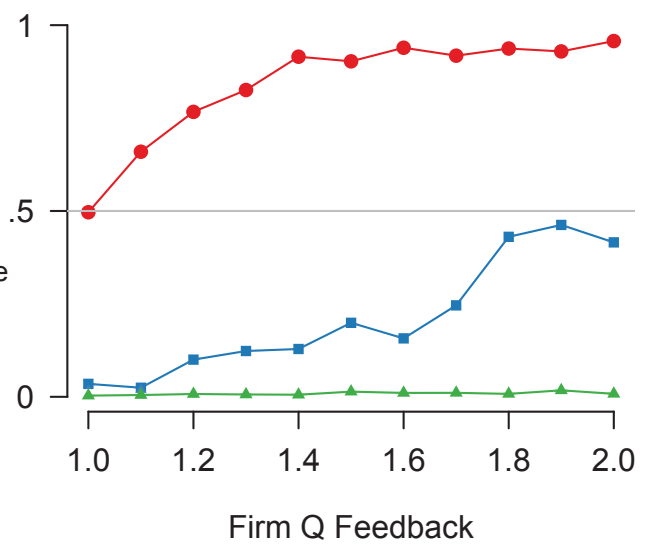

Figure 2: Initial advantage versus Quality (level of feedback) when feedbacks are uncertain. Firm Q has average feedbacks ranging from 1 to 2 shown on the horizontal axis. Firm IA has average feedback 1 and an equal, double, or five-fold initial advantage represented by the three lines in the graph. In the left panel feedbacks occur with probability $1 / 4$ and in the right panel they occur with probability $1 / 10$. 


\section{Firm IA Median Share After 10,000 Sales}

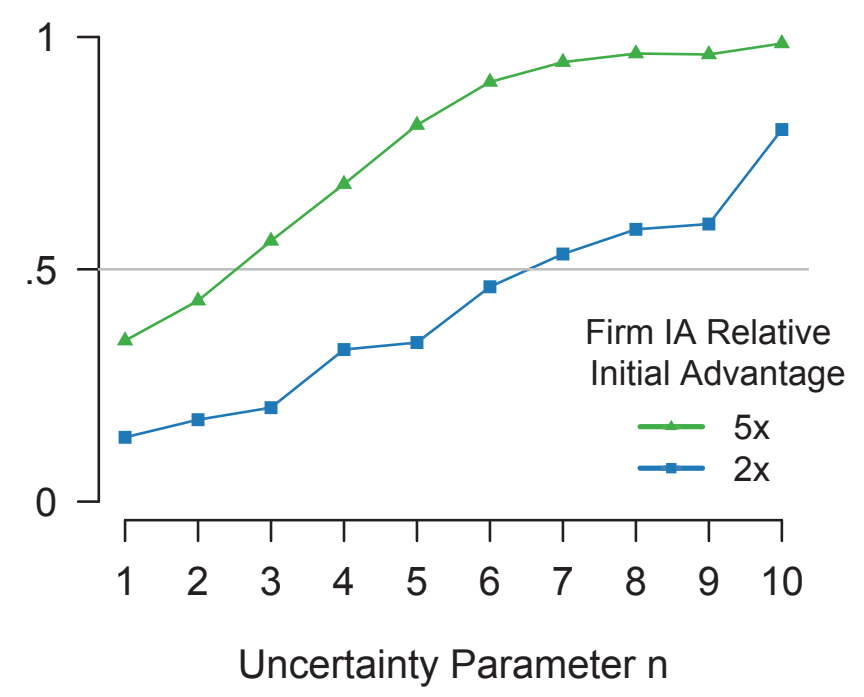

Figure 3: The benefits of the initial advantage strategy as a function of feedback uncertainty. Firm IA has either a two fold or five fold initial advantage and feedbacks $n$ with probability $1 / n$. The competing firm, Firm Q, has feedbacks $1.5 n$ with probability $1 / n$.

advantage to best a firm with a five fold initial advantage. In the right panel, when feedbacks occur for an average of one out of ten sales then even a firm with just double the initial advantage beats all of the tested quality strategies.

Figure 3 gives a different perspective on how the benefits of an initial advantage strategy change with the level of uncertainty. The figure plots the median share of Firm IA when competing against Firm Q as the level of uncertainty varies. Firm IA has either a two fold or five fold initial advantage and feedbacks $n$ with probability $1 / n$, while Firm Q has feedbacks $1.5 n$ with probability $1 / n$. As the 
figure illustrates, the more uncertain the feedbacks, the more beneficial an early advantage becomes. A five fold initial advantage beats the quality strategy as soon as feedbacks occur for fewer than one in three purchases. If feedbacks occur with probability $1 / 10$, then a five fold initial advantage is sufficient to maintain near complete market dominance after 10,000 sales in more than half of the simulations.

One way to understand why this occurs is by invoking the logic of the central limit theorem. The firm that has the initial advantage makes a sufficient number of sales to get an average positive feedback. The late entrant does not. For example, the firm with the initial advantage may get twenty sales in the first twenty five periods whereas the other firm gets only five. The variance in average feedback for the first firm will be much lower. Even if the second firm has higher quality, that higher quality might not produce higher average feedbacks for any given five draws. In effect, because the firm with the initial advantage gets lots of initial sales, it faces less uncertainty.

\section{Consistency as a Strategic Choice}

In Sections 3.1 and 3.2 we discuss how standard economic intuition applies in the urn model framework: increasing a firm's initial state or mean feedbacks increases its expected sales in any finite time. In the previous section, we demonstrated using computational results that which of these strategies is most likely to succeed after a fixed number of sales depends on the variability of the market. Lamberson 
and Page (2012) proved using a model similar to the one in this paper that more consistent feedbacks also result in higher expected market share, so just as time to market and product quality can be viewed as strategic choices so too can feedback consistency. Their theorem, stated formally below, shows that second order stochastic dominance is a sufficient condition for one distribution of uncertain positive feedbacks to result in higher expected market share than another. Thus, the firm with more consistent feedbacks will have higher expected sales even when a purchase of either product produces the same feedback in expectation.

Theorem 2. (Lamberson and Page, 2012) Suppose two firms, A and B, start in the initial state $S=(1,1)$ and have transition weights $\rho=\left(\rho_{A}, \rho_{B}\right)$. Let $F$ be the cumulative distribution function for $\rho_{A}$ and $G$ be the cumulative distribution function for $\rho_{B}$, and suppose that $F$ second order stochastically dominates $G$.

That is,

$$
\int_{0}^{\infty} h(x) d F(x) \geq \int_{0}^{\infty} h(x) d G(x)
$$

for any nondecreasing concave function h (this is equivalent to the statement $G$ is a mean preserving spread of $F) .{ }^{4}$ Then

$$
\bar{X}_{A}^{T}[S, \rho]>\bar{X}_{B}^{T}[S, \rho]
$$

for any $T \geq 2$.

\footnotetext{
${ }^{4}$ Interestingly, Theorem 2 contrasts with existing results on diffusion in networks. Generally, networks with more variable degree distributions, i.e. hubs and spokes, are more conducive to diffusion than networks in which each node has a similar number of connections (Lamberson, 2011, 2015). The difference in the urn model is due to the "dilution" effect that occurs when more balls are added to the urn: the more balls there are the less each individual ball counts.
} 
Theorem 2 reveals an asymmetry between cost reductions and social influence. As previously mentioned, cost reductions through economies of scale should produce certain positive feedbacks. In contrast, social influence produces variable feedbacks. Theorem 2 implies that if equal in expected level of positive feedback, increasing returns to scale will have a larger effect on sales than social influence. More generally, if different types of positive feedbacks differ in their distributions, so too will they differ in their effect sizes.

Consumer heterogeneity can also create variation in feedbacks from wordof-mouth. Heterogeneity may differ across product classes or even within a class. Consider a mainstream action movie that appeals to almost everyone to a moderate degree. We might assume each person who sees the film recommends it to one other friend. Contrast this with an edgy independent documentary that appeals to a niche market. Within that market, suppose that some love the film and others find it too avant garde. Perhaps only one in ten audience members who see the film recommend it, but that each of these recommends the film to ten of their friends.

The theorem implies that although the two films have identical expected social effects, in expectation the action film will produce a larger spillover. If we assume the initial audience were of identical size, the action film should outsell the documentary.

The market dominance of the action film occurs from variation in social influence. If consumers are less likely to view the documentary independently of the social influence effects, this will only compound the differences in the box office 
success of the movies.

Notice that this same conclusion applies to novel product categories where consumers know little about the item until they bring it home and try it or learn from someone who has. Easy to use products may have a market advantage over more complicated products even if the added complexity results in greater benefits. Increasing ease of use, a strategy that Apple has pursued relentlessly, increases consistency of feedback and sales. ${ }^{5}$

Relatedly, a firm might influence the certainty of positive feedbacks by making their product more recognizable, what Jonah Berger calls making the product "public" (Berger, 2016). Many successful products in industries with strong positive feedbacks have distinctive visual designs that make it certain they will be recognized, like the white ear buds of an iPod (McFedries, 2005) or the distinctive shape of a Toyota Prius. The previous theorem implies that a product with high but randomly recognized positive feedback can be outsold by a more recognizable product with lower feedbacks - even when in expectation the feedback levels are the same.

A final implication concerns quality control. Imagine two competing restaurants, Sometimes Amazing and Always Decent. The two restaurants depend on reputation through word-of-mouth to generate business. The chef at Sometimes

\footnotetext{
${ }^{5}$ Examples from Apple include development of the computer mouse for popular use (Gladwell, 2011) and the touch screen interface of the iPhone. Steve Jobs, Apple's longtime CEO was quoted as saying, "The main thing in our design is that we have to make things intuitively obvious." Famously, in designing the Apple iPod, Job's demanded that any function should be reachable in three intuitive clicks. "If he couldn't figure out how to navigate to something, or if it took more than three clicks, he would be brutal," wrote one biographer (Isaacson, 2012).
} 
Amazing is hit or miss; the lucky customers that come on one of her "on days" will recommend it to anyone they meet, while those that come on an off day are unlikely to mention their lackluster meal. At Always Decent the food is consistently good, but never outstanding. Everyone that goes there recommends it to a few close friends, but doesn't go out of their way to share their experience. Theorem 2 says that even if, on average, customers of either restaurant recommend it to the same number of people, Always Decent will outperform Sometimes Amazing. A similar dynamic could play out in many service industries such as banking or insurance. Variation in quality will also affect demand for non-service products such as laptop computers or automobiles; it is not just the average quality of these products that counts, but also the variance in quality.

When compared to the initial advantage strategy and the quality strategy, reducing variation in feedbacks has a surprisingly strong effect. Figure 4 shows what happens when a firm taking an initial advantage strategy (left panel) or a quality strategy (right panel) competes against a firm with constant feedbacks. The left panel shows the median share of Firm IA after 10,000 purchases from 1000 simulations in which Firm IA has either an equal, two fold, or five fold initial advantage, but has feedbacks $n$ with probability $1 / n$, while the competing firm has fixed feedbacks 1 with probability 1 . Once feedbacks become sufficiently uncertain, reducing uncertainty is more effective than establishing an initial advantage. Thus, if getting to market early comes at the cost of feedback consistency, a firm may do best to wait. The right panel tells a similar story when comparing a firm using the quality strategy to a consistent firm. Here, Firm Q has feedbacks $\alpha$ n 
Firm IA Median Share

After 10,000 Sales

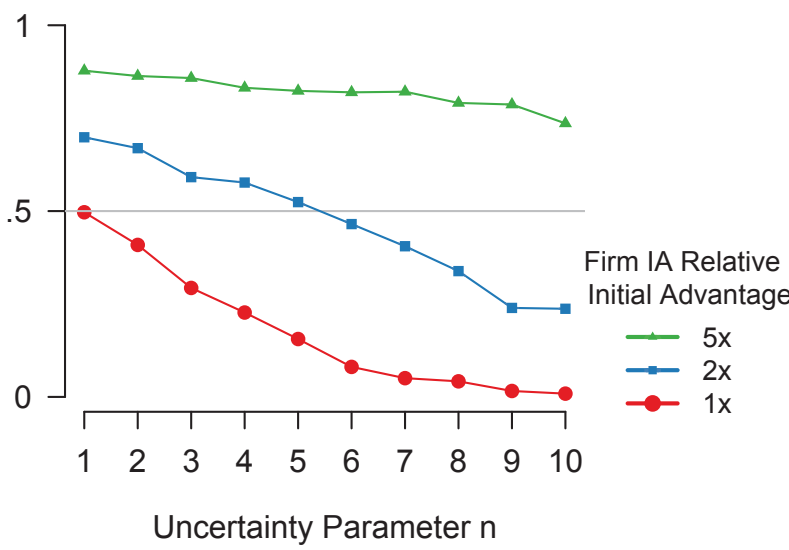

Firm Q Median Share

After 10,000 Sales

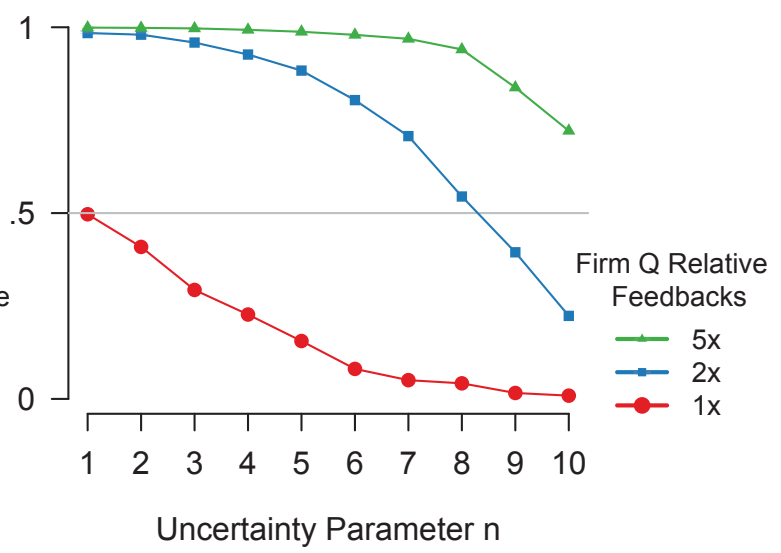

Figure 4: Left panel: Median share of Firm IA after 10,000 purchases from 1000 simulations in which Firm IA has either an equal, two fold, or five fold initial advantage, and has feedbacks $n$ with probability $1 / n$, while the competing firm has fixed feedbacks 1 with probability 1. Right panel: Median share of Firm Q after 10,000 purchases from 1000 simulations in which Firm Q has feedbacks $\alpha n$ with probability $1 / n$ and competes against a firm with feedbacks 1 with probability 1 . 
with probability $1 / n$ and competes against a firm with feedbacks 1 with probability 1 . As the graph shows, in some cases its more important to be consistent than better.

\section{Conclusion}

In this paper we construct a class of models of firm competition with positive feedbacks and use analytic and computational methods to compare two strategies: gaining an initial advantage or improving product quality. The conventional wisdom holds that increasing initial advantage through aggressive marketing tactics can be costly in the short run, but these expenses can be recouped by later sales to locked-in customers (Shapiro and Varian, 1999). When feedbacks are certain, we find the conventional wisdom incorrect: the benefits of increasing initial market presence are short lived relative to those from increasing the level of feedbacks. When feedbacks are variable, early entry produces larger returns.

We can infer from that second finding that higher quality firms should seek consistent feedbacks by reducing variation in product quality and in consumers' experiences. Kalish and Lilien (1986) quote a cautionary tale from Peters and Waterman, Jr. (1982) that illustrates the potential pitfalls of choosing the initial advantage strategy at the expense of quality and consistency:

We rushed to the market with a new product because it was clearly a superior technical device. We wanted to grab market share quickly. But reliability was awful. Our share peaked at fourteen percent and 
is now down below eight percent, while we should have had thirty or thirty-five percent of the market. A six month delay in introduction to iron out the bugs would have done it. Damn it. (Peters and Waterman, Jr., 1982, p. 179)

The failure of the extant literature to consider variation in feedback might seem puzzling given the general acceptance of quality control as a key strategic element and the magnitude of its effect in our model. However, keep in mind that introducing feedback uncertainty in isolation produces no long run effect when analyzing the impact of either initial advantage or quality independently.

However, as we show here, when we analyze markets in which products can differ in both quality and time to market, i.e. almost all markets, feedback variation becomes a key strategic lever. Firms benefit from improved quality control and from reducing variation in consumptive value. Consistent messaging and branding that reduce feedback variation will help to maintain market share.

Our findings also have implications for firms who target new products to the more extreme population of "early adopters" hoping to gain momentum from positive feedbacks that propel the product to break into the mainstream (Danko and MacLachlan, 1983; Rogers, 2003). Our model suggests that this would only be a prudent strategy with homogenous early adopters. If the preferences of early adopters differ from one another or from those of the mainstream market (Hawkins, Roger and Coney, 1989; Moore, 1999; Slater and Mohr, 2006), a targeted approach increases the variation in positive feedbacks with the early adopters and for the general population. Both effects slow the product's takeoff. 
Faith in these strategic insights must be tempered by an awareness of the high level of abstraction of the urn model. Abstract, simple models have both strengths and weaknesses. On the one hand, by leaving out the specific details regarding the mechanism that generates the feedbacks, they enable the establishment of general results that apply to any situation in which the purchase of a product increases the likelihood of future purchases. On the other hand, by not including details such as pricing, and costs of production, research and development, and advertising on the supply side, and by omitting any fine grained assumptions about consumer preference on the demand side, the models cannot be used to analyze more nuanced production, marketing, and branding strategies. That said, it is possible to draw further insights from the model. For example, if increasing the level of feedbacks in a particular industry has high costs, then the potential effectiveness of that strategic option is limited. Or, if a firm can quickly make product changes after the initial rollout to improve quality or better match consumer preferences, then our findings would suggest that they would command a much larger market share.

An interesting avenue for future research is the inclusion of strategic pricing. Pricing might well be used, as in the insulated competition literature described in the introduction, to overcome disadvantages faced by a firm in our simple model. For example, low prices could subsidize consumer switching to a late entrant when a competitor has an established initial advantage. Similarly, when feedbacks are uncertain, prices could serve to help stabilize demand and network effects. This seems to be the strategy employed by Uber and other ride-sharing platforms that 
use "surge pricing" to ensure predictable availability of rides. ${ }^{6}$

As information goods make up an increasingly large portion of the global economy, these insights are more important than ever. Positive feedbacks in their many forms - network externalities, learning curves, information cascades, increasing returns, and social learning - have always been present in markets, but in economies that consist primarily of physical goods limitations on production act as a brake on their effects. Producers who benefit from positive feedbacks can raise prices, or in the case of automobile companies, not offer discounts, but manufacturing constraints limit the extent to which they can exploit positive feedbacks, which in turn limits the strategic significance of the feedbacks. In these industries a firm that grows too fast can overshoot their capacity resulting in a rapid decline (Sterman, Henderson, Beinhocker and Newman, 2007). ${ }^{7}$

In contrast, weightless goods (Coyle, 1999), which occupy a growing share of the market, suffer from little or no production constraints. When the online game Monument Valley was featured on the hit show House of Cards in late February 2015, the very next day its iPhone games sales rank leapt from outside the top twenty-five games to the top five (Michaeli, 2015). To meet this demand, no new plants had to be opened, no new shifts had to be added, and no supply chains had to be brokered. Any and all positive feedbacks that accrued from the product placement could be instantly exploited. The ability to gain the full benefit of positive

\footnotetext{
${ }^{6}$ We thank an anonymous reviewer for suggesting this potential model extension and the surge pricing example.

${ }^{7} \mathrm{~A}$ similar dynamic can play out in service industries. See for example the classic business school case of People Express airlines (Beer, 1990).
} 
feedbacks in the weightless economy combined with increased virtual networking that amplifies social influence make understanding strategies for competing in the presence of positive feedbacks essential for today's managers.

We conclude on a cautionary note. Positive feedback "new" economy thinking suggests the importance of being first to market. Some of that intuition was based on empirical observation and some was built on stark models of increasing returns. As we showed in the paper, being first to market may create less long term value than having the better product. Standard economic logic - lower prices, higher quality - holds sway in a richer model.

And yet, when we add uncertainty, the results reversed. Early entry again matters. With variable feedbacks, being first to market mattered more because getting market share, in effect, reduces the effect of uncertainty. The logic, as we covered in detail, relies on the central limit theorem: Early market share means that you get more draws, so the sample mean approximates the true mean. Overall, our results suggest no one size fits all intuition. Optimal strategies will be contingent on market specifics and on the mechanisms that produce the positive feedbacks.

\section{A Arthur's Urn Model}

In the model of lock-in described by Arthur (1989), the process also begins with an urn that initially contains one red and one blue ball. In this model, balls in the urn can be thought of as representing aggregate sales of the two firms. At each time $t=1,2,3, \ldots$, a consumer arrives and purchases one of the two products, 
thus adding a ball of the corresponding color to the urn. The probability that the color of the ball added at time $t$ is red is given by a function $f_{t}\left(P_{r}^{t}\right):[0,1] \rightarrow[0,1]$ which depends on the time $t$ and the proportion $P_{r}^{t}$ of red balls in the urn at time $t$. The probability that the added ball is blue is $1-f_{t}\left(P_{r}^{t}\right)$. Arthur et al. (1983) prove that, given some technical conditions, if the sequence of functions $f_{t}$ converge to a function $f$, then $P_{r}^{t}$ will converge to a stable fixed point of $f$. The Pólya process is the special case of this model in which $f_{t}\left(P_{r}^{t}\right)=P_{r}^{t}$ (i.e. the probability of adding a red ball is exactly equal to the proportion of red balls in the urn). In this case, the $f_{t}$ are the same for all $t$ and trivially converge to $f(x)=x$. Every point $x \in[0,1]$ is a stable fixed point of this function, so any possible proportion of red balls is a potential limit of the process.

In the best known example of Arthur's model, the functions $f_{t}$ are defined by

$$
f_{t}\left(P_{r}^{t}\right)= \begin{cases}0 & \text { if } P_{r}^{t}<\frac{1}{2}-\frac{\delta}{t} \\ \alpha & \text { if } \frac{1}{2}-\frac{\delta}{t} \leq P_{r}^{t} \leq \frac{1}{2}+\frac{\delta}{t} . \\ 1 \quad & \text { if } P_{r}^{t}>\frac{1}{2}+\frac{\delta}{t}\end{cases}
$$

One can interpret this model as capturing consumer choice in the following way. Imagine that absent any positive feedbacks, each consumer has a preference for either the red or the blue product. The constant $\alpha$ gives the fraction of consumers of the red type. When both products command similar shares, consumers purchase the product corresponding to their type, but when one of the products gains a sufficient market share, both consumer types purchase the market lead- 
ing product. Once again, this could be because of network externalities, social influence, or lower costs due to returns to scale.

Given the formal assumptions, as $t$ approaches infinity, the functions $f_{t}$ converge to

$$
f\left(P_{r}^{t}\right)= \begin{cases}0 & \text { if } P_{r}^{t}<\frac{1}{2} \\ \alpha & \text { if } P_{r}^{t}=\frac{1}{2} \\ 1 & \text { if } P_{r}^{t}>\frac{1}{2}\end{cases}
$$

The only stable equilibria of this system occur at $f(0)=0$ and $f(1)=1$, and therefore the market converges to a "winner-take-all" outcome. ${ }^{8}$ The key to producing lock-in is in the specification of the functions $f_{t}$. In some sense, a ball is never drawn from the urn - balls are only added to the urn as specified by $f_{t}$. Thresholds built in to the functions $f_{t}$ make the probability that a ball of a given color is added become zero in finite time, which can never happen in the Pólya process or the generalized Pólya process that we employ.

\section{References}

Arthur, W. Brian, “Competing Technologies, Increasing Returns, and Lock-In

\footnotetext{
${ }^{8}$ Note that we have phrased our exposition of Arthur's example in terms of the corresponding urn process. We have not seen this process (and in particular the transition functions $f_{t}$ ) described explicitly elsewhere. Typically the example is presented in terms of the payoffs received by the two types of agents from adopting the different technologies (Arthur, 1989), which makes the example easier to motivate, but obscures the connection with the general analysis of Arthur et al. (1983).
} 
by Historical Events," The Economic Journal, 1989, 99, 116-131.

_ , "Increasing Returns and the New World of Business," Harvard Business Review, 1996, 74, 100-111.

_, Yu Ermoliev, and Yu Kaniovski, “On Generalized Urn Schemes of the Pólya Kind," Cybernetics, 1983, 19, 61-71.

Athreya, K. B., "On a Characteristic Property of Pólya's Urn," Studia Scientiarum Mathematicarum Hungarica, 1969, 4, 31-35.

Beer, Michael, "People Express Airlines: Rise and Decline," Harvard Business School Case, 1990, 490-012.

Berger, Jonah, Contagious: Why things catch on, Simon and Schuster, 2016.

Besen, Stanley M and Joseph Farrell, "Choosing how to compete: Strategies and tactics in standardization," The Journal of Economic Perspectives, 1994, 8 (2), 117-131.

Blackwell, David and James B. MacQueen, "Ferguson Distributions via Pólya Urn Schemes," The Annals of Statistics, 1973, 1 (2), 353-355.

Cowan, Robin, "Nuclear Power Reactors: A Study in Technological Lock-in," The Journal of Economic History, 1990, 50 (3), 541-567.

- and Philip Gunby, "Sprayed To Death: Path Dependence, Lock-in and Pest Control Strategies," The Economic Journal, 1996, 106, 511-542. 
Coyle, Diane, The weightless world: strategies for managing the digital economy, MIT Press, 1999.

Danko, W.D. and J.M. MacLachlan, "Research to accelerate the diffusion of a new invention," Journal of Advertising Research, 1983, 23 (3), 39-43.

David, Paul A., "Clio and the Economics of QWERTY," The American Economic Review, 1985, 75 (2), 332-337.

De Vany, Arthur and W. David Walls, "Bose-Einstein Dynamics and Adaptive Contracting in the Motion Picture Industry," The Economic Journal, 1996, 106 (439), 1493-1514.

Dybvig, Philip H and Chester S Spatt, "Adoption externalities as public goods," Journal of Public Economics, 1983, 20 (2), 231-247.

Farrell, Joseph and Garth Saloner, "Standardization, Compatibility, and Innovation," RAND Journal of Economics, 1985, 16 (1), 70-83.

_ and Paul Klemperer, "Coordination and Lock-in: Competition with Switching Costs and Network Effects," Economics Papers 2006-W07, Economics Group, Nuffield College, University of Oxford 2006.

Fleder, Daniel and Kartik Hosanagar, "Blockbuster culture's next rise or fall: The impact of recommender systems on sales diversity," Management Science, 2009, 55 (5), 697-712. 
Fudenberg, D. and J. Tirole, "Pricing a network good to deter entry," The Journal of Industrial Economics, 2000, 48 (4), 373-390.

Fudenberg, Drew and Jean Tirole, "Learning-by-doing and market performance," The Bell Journal of Economics, 1983, 14 (2), 522-530.

Ghemawat, P. and M. Spence, "Learning Curve Spillovers and Market Performance," Quarterly Journal of Economics, 1985, 100 (5), 839-852.

Gladwell, Malcolm, "Creation Myth: Xerox PARC, Apple, and the truth about innovation," The New Yorker, 2011, May 6.

Greenberg, D., "Modeling Criminal Careers," Criminology, 1991, 29, 17-46.

Grindley, Peter, "Winning standards contests: using product standards in business strategy,” Business Strategy Review, 1990, 1 (1), 71-84.

Hawkins, D.I., J. Roger, and K.A. Coney, Consumer Behavior: Implications for Marketing Strategy, BPI/Irwin, 1989.

Hossain, Tanjim and John Morgan, “The quest for QWERTY," The American Economic Review, 2009, 99 (2), 435-440.

Isaacson, Walter, "How Steve Job's Love of Simplicty Fueled a Computer Revolution," Smithsonian Magazine, 2012, September.

Johnson, Norman Lloyd and Samuel Kotz, Urn Models and Their Application: An Approach to Modern Discrete Probability, New York: Wiley, 1977. 
Kalish, Shlomo and Gary L Lilien, "A market entry timing model for new technologies," Management Science, 1986, 32 (2), 194-205.

Katz, Michael L. and Carl Shapiro, "Network Externalities, Competition, and Compatibility," The American Economic Review, 1985, 75 (3), 424-440.

Khanin, Kostya and Raya Khanin, "A Probabilistic Model for the Establishment of Neuron Polarity,” Journal of Mathematical Biology, 2001, 42 (1), 26-40.

Lamberson, P. J., "Linking Network Structure and Diffusion Through Stochastic Dominance," Connections, 2011, 31 (1).

_ , "Diffusion in Networks," in "The Oxford Handbook of the Economics of Networks," Oxford University Press, 2015.

_ and Scott E Page, "The effect of feedback consistency on success in markets with positive feedbacks," Economics Letters, 2012, 114 (3), 259-261.

Levene, Mark, Trevor Fenner, George Loizou, and Richard Wheeldon, "A Stochastic Model for the Evolution of the Web," Computer Networks, 2002, 39, $277-287$.

LiCalzi, Marco and Oktay Surucu, "The power of diversity over large solution spaces," Management Science, 2012, 58 (7), 1408-1421.

Liebowitz, S. J. and Stephen E. Margolis, “The Fable of the Keys,” Journal of Law and Economics, 1990, 33 (1), 1-25. 
_ and _, "Network Externality: An Uncommon Tragedy," The Journal of Economic Perspectives, 1994, 8 (2), 133-150.

_ and _ , "Path Dependance, Lock-in, and History," Journal of Law, Economics and Organization, 1995, 11 (1), 205-226.

Liebowitz, SJ and S. Margolis, Winners, Losers \& Microsoft, Independent Institute, 2001.

McFedries, P., “Technically Speaking: The iPod People," Spectrum, IEEE, 2005, 42 (2), 76-76.

Michaeli, Ariel, "House of Cards Stacks the Deck for Monument Valley's Success Across Major App Stores," http://blog.appfigures.com/house-ofcards-stacks-the-deck-for-monument-valleys-success-across-major-app-stores/ March 32015.

Moore, G.A., Crossing the Chasm: Marketing and Selling High-tech Products to Mainstream Customers, HarperBusiness, 1999.

Page, Scott E., "Path Dependence," Quarterly Journal of Political Science, 2006, $1,87-115$.

Pemantle, Robin, "A Survey of Random Processes with Reinforcement," Probability Surveys, 2007, 4, 1-79.

Peters, Thomas J. and Robert H. Waterman, Jr., In Search of Excellence, New York: Harper \& Row, 1982. 
Rogers, Everett M., Diffusion of Innovations, New York: Simon \& Schuster, 2003.

Shapiro, Carl and Hal R. Varian, Information Rules: A Strategic Guide to the Network Economy, Cambridge, MA: Harvard Business School press, 1999.

Slater, S.F. and J.J. Mohr, "Successful Development and Commercialization of Technological Innovation: Insights Based on Strategy Type," Journal of Product Innovation Management, 2006, 23 (1), 26-33.

Spence, A, "The Learning Curve and Competition," The Bell Journal of Economics, Apr 1981, 12 (1), 49-70.

Spence, A Michael, "Investment strategy and growth in a new market," $J$. Reprints Antitrust L. \& Econ., 1979, 10, 345.

Sterman, John D., Rebecca Henderson, Eric D. Beinhocker, and Lee I. Newman, "Getting Big Too Fast: Strategic Dynamics with Increasing Returns and Bounded Rationality," Management Science, 2007, 53 (4), 683-696.

Watts, Duncan J and Steve Hasker, "Marketing in an Unpredictable World," Harvard Business Review, 2006, 84 (9), 25-30.

Weyl, E Glen, "A price theory of multi-sided platforms," The American Economic Review, 2010, 100 (4), 1642-1672. 
_ and Alexander White, "Let the Right 'One' Win: Policy Lessons from the New Economics of Platforms," Coase-Sandor Working Paper Series in Law and Economics, 2014, (709).

White, Alexander and E Glen Weyl, "Insulated platform competition,” Available at SSRN: https://ssrn.com/abstract=1694317 2016. 